\title{
Forestry Research Advisory Council of Canada Annual Report for 1993
}

\author{
April 1994
}

\section{Summary}

The Forest Accord that flowed from the Forest Congress of March 1992 carries firm commitments to "maintain and enhance the long term health of our forest ecosystems, for the benefit of all living things both nationally and globally." It recognizes forestry research as vital in attaining this goal.

The Forestry Research Advisory Council of Canada (FRACC) has provided advice on forestry research priorities and policies to the Canadian Forest Service (CFS) since 1983. The Council is much encouraged by the Accord's strong emphasis on research.

As a result of the 1987 decision by the Canadian Council of Forest Ministers (CCFM), forest research advisory councils (FRACs) are now functioning in most provinces. FRACC works closely with these groups and for the past five years, with their assistance, has prepared an annual overview of forestry research priorities and concerns across Canada. Over the past year, the Council has reviewed its role and its working arrangements with the FRACs.

In this 1993 report, Council makes the following recommendations:

Recommendation 1. CFS research programs to improve and foster sustainable forest management should be aimed at maintaining viable, diverse forest ecosystems using techniques that mimic natural processes as much as possible, to produce an appropriate mix of values.

Recommendation 2. The CFS should complete the update of the forestry research inventory and then give attention to further refining the software system. In particular, it should be made more flexible and adapted to manipulation by existing commercially available software.

Recommendation 3. All agencies concerned with Canadian forest research should be urged to discuss and study the report Toward a National Forest Science and Technology Agenda for Canada.

Recommendation 4. The CFS should strongly support the concept of alternating annual activities. An overview of research priorities could be conducted in odd-numbered years; then in even-numbered years, FRACC and representatives of the provincial and territorial councils could hold a workshop to examine a major research topic in depth and present the results and conclusions to the CCFM.

Recommendation 5. The CFS should ensure that sufficient funding is available to cover at least three meetings of Council each year. It should also make a reasonable amount of staff time or contract funds available to Council for the conduct of analysis and studies.

Recommendation 6. The CFS should review Council's terms of reference, and give direction on whether Council should make recommendations that go beyond the research programs of the CFS, and whether it should include forest products research in its examination of issues and priorities.
The funding of forest research is a matter of serious concern, particularly the need to provide stable, long-term funding, because forest research is, by its nature, long term. No specific recommendations were prepared in 1993 but Council will continue to give this question close attention in 1994.

Forest research priorities across the country were again assessed in cooperation with the provincial and territorial FRACs. It was agreed that forest research must be targeted to enable forest managers to:

- Sustain the diversity and resilience of the forest ecosystems.

- Improve forest health and resistance to pests.

- Increase forest productivity for all values.

- Reduce forest management and fire protection costs.

- Access all available knowledge and data in making decisions.

- Determine the socio-economic value of Canadian forests.

- Improve profits and competitiveness in the forest industry.

Forest research in Canada is considered to be reasonably well focused on these questions, but more effort is required to ensure long-term funding and to improve application of results.

Council will hold three regular meetings in 1994. During the year it will give attention to:

1. Global trends affecting forestry — including five or six major issues requiring research attention, and the implications they all have for forest research priorities.

2. Progress of the forest research inventory.

3. Development of a proposal for research coordination and support, as requested by the Forest Sector Advisory Council.

4. How research is categorized, performed, and funded in Canada - to provide information useful in further improving the ongoing forest research inventory, and as a basis for the proposal on research funding being considered by Council.

\section{Introduction}

The Forest Accord that flowed from the Forest Congress held in Ottawa in March 1992 has the strong support of the Canadian Council of Forest Ministers (CCFM). The Accord carries firm commitments to "maintain and enhance the long term health of our forest ecosystems, for the benefit of all living things both nationally and globally, while providing environmental, economic, social and cultural opportunities for the benefit of present and future generations." Research is recognized as vital in attaining this goal, and the Accord contains strong commitments to forest research.

Since 1983 the Forestry Research Advisory Council of Canada (FRACC) has advised the Canadian Forest Service (CFS) on broad national forest research priorities and policies. The Council is much encouraged by the Forest Accord's emphasis on research.

In 1987, under the aegis of the CCFM, forest research advisory councils (FRACs) were established in each province 
and territory. FRACC has worked with these councils and for each of the past five years has prepared an annual Canada-wide overview of forest research priorities and concerns.

Over the past year, Council has reviewed its role and mandate, and its working arrangements with the FRACs. Some conclusions and recommendations on these and other matters are presented later in this report.

The 1993 Council members are listed in Appendix I. Two meetings were held during the year: in Ottawa on May 23-24 and in Winnipeg on October 18-19. Deputy Minister Jean Claude Mercier attended the May meeting and Assistant Deputy Minister Yvan Hardy was at both meetings. Council appreciates this continuing interest and input, and the assistance and attention of all members of the CFS.

\section{Continuing Issues and Concerns in 1993 Managing Forest Landscapes}

It is becoming increasingly accepted that Canada should rely on a variety of approaches in managing its forest estate. On highvalue lands situated close to mills, intensive plantation culture using genetically improved stock is often appropriate. In other areas, it is more suitable to employ less intensive techniques designed to yield an agreed-upon mix of outputs while sustaining the natural ecological integrity and biological diversity of the landscape.

Such an approach has been described as "natural forest landscape management." It makes the ecosystem the basis of management and mimics natural processes as much as possible. It maintains a natural mix of ecosystems at various developmental stages, and at the same time yields the desired outputs such as timber, game, recreational opportunities, and watershed protection. Canada is in a favorable position to pursue this approach because forest ecosystems here are still in a relatively natural condition. In order to successfully apply the desirable broad range of techniques including natural forest landscape management, a much deeper understanding of forest ecosystems is required.

Recommendation 1. CFS research programs to improve and foster sustainable forest management should be aimed at maintaining viable, diverse forest ecosystems using techniques that mimic natural processes as much as possible, to produce an appropriate mix of values.

\section{Inventory of Forest Research in Canada}

The research inventory project was begun some years ago in response to a suggestion by FRACC. Subsequently, Council recommended that the inventory be maintained and made available to managers and researchers. Some difficulties were encountered during the first update. Council recommended that the questionnaire and procedures be altered and that full use be made of existing research inventories being conducted in at least two provinces, British Columbia and Quebec.

The system has been considerably revised and the process of gathering new data is now under way. Some questions have been raised about the new computer program. In particular, it is relatively inflexible and the resulting data file cannot be manipulated by widely available software programs such as DBase. Nevertheless, the initiative is worth pursuing and Council looks forward to the completion of the first full updating of the inventory.
Recommendation 2. The CFS should complete the update of the forestry research inventory and then give attention to further refining the software system. In particular, it should be made more flexible and adapted to manipulation by existing commercially available software.

\section{Forest Science and Technology Agenda}

Council had three members on the advisory group that helped guide this CFS initiative and has followed its progress under the leadership of Drs. Graham Page and Guy Brassard with great interest.

The report, now completed, suggests an overall framework or agenda for forestry science and technology programs in Canada and defines the role of CFS within that framework. It proposes principles that should typify a forestry science and technology agenda or strategy for Canada, discusses current issues in relation to the principles, and considers the implications for the country's forest science and technology agencies. Commendably, the CFS is now working to apply the conclusions and recommendations to its own programs.

Council feels that it would be worthwhile if all forest research agencies could study and discuss the conclusions and suggestions in the report. One or more workshops or seminars might be considered.

Recommendation 3. All agencies concerned with Canadian forest research should be urged to discuss and study the report Toward a National Forest Science and Technology Agenda for Canada.

\section{Funding Forest Research}

One of the most serious impediments to effective prosecution of forest research in Canada is the uncertain nature of much of the funding provided by governments and industry. The lack of long-term funding has an insidious effect, particularly on forestry research. It tends to focus research on problems that seem amenable to short-term approaches and to quick resolution. This is most serious because many problems facing the managers of Canada's forest landscapes today can be solved only by longterm research, which must be carefully planned and pursued over many years to arrive at valid conclusions.

Some time ago the Forest Sector Advisory Council of Canada drew attention to this problem and asked FRACC to examine it and suggest improvements. A committee of Council has prepared a draft proposal for the creation of a series of provincially or regionally based forest research funding councils that would be supported by both the public and private sectors. Council will devote further attention to this matter in 1994.

\section{Research Priorities as Identified by the Regional Forest Research Advisory Councils across Canada}

In 1993, FRACC, in cooperation with provincial and territorial forest research advisory councils, prepared the fifth annual review of forest research priorities for the CCFM.

Eight issues likely to affect future research priorities were identified by more than one of the councils, as follows:

1. Global trade, competition, and world public opinion.

2. Concern and input about sustainable forestry and environment. 
3. Public participation.

4. New policies on forestry, tenure, sales, and forest protection.

5. Lack of long-term research funding, communication, and coordination.

6. Shortage of fibre, and long-term viability of the industry.

7. Land claims, and forestry on aboriginal lands.

8. Increasing need for information at all levels.

Other concerns include climate change, government debt, population growth and shifts, protected forests, and old-growth forests.

These major issues were of course central to the consideration of priorities for research. The top five priorities from each council were reviewed and considered in relation to one another to produce a list of 11 high priority forest research topics. They are listed here in descending order of priority.

1. Integrated forest landscape management systems and decision support.

2. Inventory, growth and yield, ecological site classification.

3. Ecosystem functioning, soil and biodiversity conservation.

4. Pest and weed management, and alternatives to chemicals.

5. Ecological effects of natural and human disturbances.

6. Lower cost silviculture and harvesting, natural regeneration.

7. Forest fire management and control.

8. Socio-economic knowledge and resolution of resource use conflicts.

9. Mixed-wood management.

10. Incentives for private investment.

11. Planting stock quality and tree improvement.

These priorities and issues were discussed at a joint meeting of FRACC and representatives from the provincial and territorial advisory councils in May 1993. All present strongly agreed that research is mandatory to provide the information managers need to resolve resource use conflicts and manage forest ecosystems sustainably for all values. Forest management systems must ensure that a suitable mix of values is produced and at the same time the natural diversity and structure of the country's forest ecosystems is maintained.

Forestry research in Canada is considered to be reasonably well focused on these questions, but more long-term funding is needed and local application of research results must be improved.

Consideration and review of the priorities raised by the regional FRACs led FRACC to some general conclusions about the principles that should guide current forest research. Forest managers need research results that will assist and enable them to meet the following challenges:

- Sustain the diversity and resilience of the forest ecosystems.

- Improve forest health and resistance to pests.

- Increase forest productivity for all values.

- Reduce forest management and fire protection costs.

- Access all available knowledge and data in making decisions.

- Determine the socio-economic value of Canadian forests.

- Improve profits and competitiveness in the forest industry.

The usefulness of the annual survey of research priorities was discussed both within FRACC and with the FRACs. The annual meeting between FRACC and representatives of the FRACs is very useful for the exchange of comment and ideas concerning research needs, progress, and priorities. In addition, the annual presentation to CCFM is worthwhile to keep ministers informed on research needs and the importance of research in solving some of the perplexing policy and technical questions they and their forest managers face.

It was concluded that a survey of priorities every year is, in the light of experience, unnecessary because priorities do not change fast enough. A biennial priorities review is recommended for presentation to CCFM and subsequent publication. In the alternate years a workshop is suggested involving FRACC and representatives from the FRACs to examine a major research topic in depth and present the results and conclusions to the CCFM. A report could be published if appropriate and distributed to the major parties involved in the forest sector.

Recommendation 4. The CFS should strongly support the concept of alternating annual activities. An overview of research priorities could be conducted in odd-numbered years; then in even-numbered years, FRACC and representatives of the provincial and territorial councils could hold a workshop to examine a major research topic in depth and present the results and conclusions to the CCFM.

\section{FRACC'S Role and Functioning}

During 1993, FRACC held only two meetings, one of which included the annual joint session with representatives of the provincial and territorial research advisory councils. Fewer meetings were held, partly because of budgetary concerns but also in some measure because of constraints on members' time.

Experience has shown that at least three meetings a year are necessary to maintain continuity and provide reasoned advice to the CFS. Council has noted the comments made in the Science and Technology Agenda prepared by Page and Brassard to the effect that FRACC has not adequately addressed strategic research and development issues and has not made recommendations that go beyond the CFS. These matters have also been a concern to Council for some time and it discussed them in some detail in 1993 seeking ways of improving FRACC's ability to provide useful advice. The Council works under several constraints: its terms of reference specifically focus its attention on the CFS; the time that members have available to devote to council affairs is limited; and Council lacks the resources for major data gathering and analysis.

The question of forest products research was also discussed. Many of the provincial research advisory councils cover forest products. FRACC, however, has only occasionally given attention to this topic and then only in a peripheral way.

Forest products research is conducted by Paprican, by Forintek, by individual forest products companies, and to some extent by universities. These organizations have their own research advisory procedures and for this reason FRACC has not become deeply involved. However, it recognizes the importance of this research and is aware that CFS plays a major role in funding Forintek.

Recommendation 5. The CFS should ensure that sufficient funding is available to cover at least three meetings of Council 
each year and make a reasonable amount of staff time or contract funds available to Council for the conduct of analysis and studies.

Recommendation 6. The CFS should review Council's terms of reference and give direction as to whether Council should make recommendations that go beyond the research programs of the CFS, and whether it should include forest products research in its examination of issues and priorities.

\section{Plan of Action for 1994}

Council will hold at least three regular meetings in 1994, one in Ottawa, one in the east, and one in the west. During the year it will give attention to the following questions and concerns:

1. Continue consideration of global trends affecting forestry; set out a framework of five or six major issues requiring research attention; and evaluate the general implications these have for forest research priorities.

2. Monitor the progress of the forest research inventory.

3. Develop a proposal for research coordination and support with forest industry participation, as requested by the Forest Sector Advisory Council.
4. Assess whether or not it would be useful to obtain additional information and analysis on how forest research is performed and funded in Canada. Such a review could give particular attention to the lack of long-term funding for research and how linkages are formed and maintained. Attention could also be given to how research is categorized, since efforts to analyze research program have been hampered by a lack of an agreed-upon "taxonomy of research." The review would update and expand previous reports by Drs Solandt and Place on the state of forestry research in Canada. It would provide information useful in further improving the ongoing forest research inventory, and as a background for the proposal on research funding now being considered by Council.

\section{Actions Stemming from Council's 1992 \\ Report}

Forestry Canada again provided a year-end report to FRACC concerning its follow-through on FRACC's recommendations of the previous year. Council members are pleased that this practice is continuing. The report is attached as Appendix II.

\section{Appendix I. FRACC Membership for 1993}

\section{Provincial Representation}

Dr. Ted Baker

Director, Research Branch

British Columbia Forest Service

31 Bastion Square

Victoria, BC, V8W 3E7

Mr. John Goodman

Assistant Deputy Minister, Administration

Ministry of Natural Resources

99 Wellesly Street West

Toronto, ON, M7A 1W3

Monsieur Jean-Guy Davidson

Chef du service de la recherche appliquée

Ministère des Ressources naturelles

2700, rue Einstein, bloc b.1.190,

Sainte-Foy, QC, G1P 3W8

Mr. Ian Taviss

Research Coordinator

New Brunswick Executive Research Council

H.J. Flemming Forestry Centre

Fredericton, NB, E3B 6H6

Mr. Murray Little

Saskatchewan Department of

Natural Resources

Forestry Branch

Box 3003

Prince Albert, SK, S6V 6G1

\section{Industry Representation}

Mr. Jack W. Toovey, RPF

(Chairman of FRACC through 1992)

2976 William Avenue

North Vancouver, BC, V7K 1 Z6
Tel: (604) 387-6720

Fax: (604) 387-0046

Tel: (416) 965-7106

Fax: (416) 324-3683

Tel: (418) 643-7994

Fax: (418) 643-2165

Tel: (506) 452-6932
Tel: (306) 953-2486

Tel: (604) 985-8680

Fax: (604) 985-8528
Mr Michael R.Innes,

Manager of Forestry, Abitibi-Price Inc.

(Chairman of FRACC)

207 Queen's Quay West, Box 102

Toronto, ON, M5J 2P5

Mr. R.W. Udell, RPF

Strategic Planning Superintendent

Weldwood of Canada Ltd.

760 Switzer Drive

Hinton, AB., T7V 1V7

(N.B. Mr Udell resigned from Council in February 1993)

Mr. Gerald Lapointe

Woodlands Section

Canadian Pulp \& Paper Association

1155 Metcalfe St., 23rd floor

Montreal, QC, H3B 4T6

Monsieur Jean Bérard

11480 , rue Pasteur

Montréal, QC, H3M 2P1

\section{Professional Representation}

Mr. W.J. Brown

General Manager

Algonquin Forestry Authority

222 Main Street West

Huntsville, ON, P0A 1 K0

\section{University Representation}

Dr. Peter J. Murphy

Faculty of Agriculture \& Forestry

Department of Forest Science

University of Alberta

Edmonton, AB, T6G 2H1
Tel: (416) 369-6742

Fax: (416) 369-6745

Tel: (403) 865-2251

Fax: (403) 865-8129

Tel: (514) 866-6621

Fax: (514) 866-3035

Tel: (514) 334-7810

\author{
Tel: $(514) 334-7810$
}

Tel: (705) 789-9647

Tel. (705) $789-9647$
Bus. tel: (403) 492-2359

Res. tel: (403) 458-9706

Fax: (403) 492-4323 
Dr. Gilles Frisque, Director

Multiregional Forestry Research Centre

University of Quebec

531, boulevard des Prairies

Laval, QC, H7N 4Z3

\section{Members at Large}

Monsieur Claude Godbout, Doyen

Faculté de foresterie

et de géomatique

Université Laval

Québec, QC, G1K 1G5

Mr. Paul Griss

Address in 1992:

Canadian Nature Federation

453 Sussex Drive

Ottawa, ON, K1N 6Z4

Current Address:

123 Walmer Road

Toronto, ON, M5R 2X8
Tel: (514) 687-5010

Fax: (514) 686-5501

Tel: (418) 656-2116

Fax: (418) 656-3177

Tel: (613) 238-6154

Fax: (613) 230-2054

Tel: (416) 926-9721

Fax: (416) 926-9721
Dr. Stan Rowe

Tel: (604) 358-7170

PO Box 11

New Denver, BC, V0G 1S0

\section{Ex Officio}

Dr. F.C. Pollett, Director General

Tel: (819) 997-1107

Science and Sustainable Development

Fax: (819) 994-3389

Directorate

Canadian Forest Service

Natural Resources Canada

351 Saint Joseph Boulevard

Hull, QC, K1A 1G5

Executive Secretary

Dr. R.J. Bourchier

R.R. 1, PO Box 255

Cantley, QC, J0X 1L0
Tel: (819) 827-0903

\section{Appendix II. Forestry Canada's Response to FRACC'S 1992 Report}

Recommendation 1. Because Canadians expect many kinds of benefits from the forest resource, Forestry Canada should increase research that will help forest managers assess all commodity and amenity values of the forest and incorporate them into integrated forest management plans.

Response. Forestry Canada is in agreement with this recommendation. Work at several of its establishments including Petawawa National Forestry Institute, Northwest Region, and Pacific and Yukon Region is emphasizing incorporation of commodity and amenity values into forest management research. All of Forestry Canada's research that is linked to the Model Forests Network also addresses this need to some extent.

Recommendation 2. To help develop multidisciplinary approaches, Forestry Canada should work with educational institutions to develop curricula for both graduate and undergraduate students that emphasize the multidisciplinary nature of forestry.

Response. While Forestry Canada agrees with the general intent of this recommendation, it is mindful of the fact that curricula of all educational institutions are strictly a matter of provincial/territorial jurisdiction. Nevertheless, Forestry Canada continues to collaborate with forestry deans and directors, and with forestry researchers in non-forestry faculties, to develop a more multidisciplinary approach to forestry teaching and research. Forestry Canada researchers frequently provide enrichment to university courses in forestry and other fields, and several of Forestry Canada's establishments have MOUs with university forestry faculties to assist in coordination and enhancement of each other's programs. In addition, Forestry Canada has indicated its support for a forum on forestry education and training, as proposed by the Association of Deans/Directors of Schools of Forestry.

Forestry Canada is strongly supportive of multidisciplinary programs such as the Tri-Council Eco-research Program, recently established under the federal Green Plan. In addition, the Department will consult more closely with both the Natural Sciences and Engineering Research Council (NSERC) and the Social Sciences and Humanities Research Council (SSHRC) on the increasingly multi-disciplinary scope and needs of forestry graduate and undergraduate programs and research projects.

Recommendation 3. To help foster effective public participation in resource decisions, Forestry Canada should continue monitoring public perceptions of forestry and develop new ways of involving people in resource decisions.

Response. Forestry Canada agrees in principle with this recommendation. Several of its recent programs, in particular the Green Plan Model Forests Network, have been designed to ensure that all stakeholders are directly involved in resource management decisions, from the planning stages through to the implementation stages.

Recommendation 4. To assist young scientists in launching their careers, Forestry Canada should establish and sponsor annual forums where young scientists and senior management exchange ideas and information.

Response. Forestry Canada agrees in principle with this recommendation, and will consider sponsoring such forums as part of its Human Resources Strategy.

Recommendation 5. To promote steady progress in research, Forestry Canada should ensure overlap and training of replacement scientists when existing staff retire.

Response. Forestry Canada agrees with this recommendation and already does this in part, but will consider strengthening its efforts in this regard where opportunities and resources permit.

Recommendation 6. Forestry Canada should vigorously 
pursue completion of the update of the forestry research inventory.

Response. Forestry Canada accepts this recommendation. A database at the Petawawa National Forestry Institute has been developed on contract over the past year, and is now undergoing final checking to ensure that it meets user needs. It is expected that the final version will be ready by July 1993 . The database will be updated regularly, to ensure that reasonably current information of this type is continuously available in future.

Recommendation 7. Because of the importance of all forestry workers' attitudes and skills in implementing sound forest management, Forestry Canada should investigate methods of training and motivation and make them part of technology transfer programs.

Response. Forestry Canada agrees that all researchers must be aware of technology transfer needs and opportunities. Several research establishments are examining means of ensuring that scientists and technicians can relate to, and effectively par- ticipate in, the department's technology transfer and communications programs. The training and motivation of operational personnel is primarily a provincial and industry responsibility, but Forestry Canada will strive to ensure that its research results are communicated to those agencies in an effective and timely manner to assist them with their training and extension roles.

Recommendation 8. Forestry Canada research establishments should develop methods to incorporate economic and social criteria in research planning and project selection.

Response. Forestry Canada agrees in principle with this recommendation, and will take steps to incorporate economic and social criteria into the research planning and review processes where feasible and appropriate. A project review of the economics research program at FC-Northwest Region has recently taken place, and the report of that review panel emphasized the increasing importance of Forestry Canada's economics and social research projects to the department's overall research program, and the need for more active collaboration between them. 